\title{
HEALTH INSURANCE SYSTEM IN SERBIA - QUALITY, REFORM, FINANCIAL SUSTAINABILITY
}

\author{
Ana Gavrilović \\ The Faculty of Small and Medium Sized Business Management, University Business \\ Academy, Belgrade, Serbia

\section{Snežana Trmčić} \\ The Faculty of Small and Medium Sized Business Management, University Business \\ Academy, Belgrade, Serbia
}

\section{(c) MESTE NGO}

JEL category: D2, 014, 03, Q19

\begin{abstract}
Constrained by difficult economic situation, the health system in Serbia is facing a great challenge, and in order to overcome it and handle the gap between possibilities and expectations, it is necessary to implement economic reform of health care sector in Serbia, i.e. its decentralization, which implies improvements in providing health services while trying to find a model of financial sustainability of health care system in Serbia.

One of the most essential impulses of society to its economic and general social development is the health of its population. In fact, in addition to being a social potential, health is to be considered as an economic potential of a country as well. The need to examine health from economic point of view, as well as in the sense of sustainable economic development, is gaining in presence in the newly made circumstances of an advancing economic crisis.

There is an evident gap in the social community between the expectations of health care beneficiaries who are used to high-quality services with considerably subsidized health care and the new situation where health care institutions dispose of no funds to ensure the necessary prerequisites for providing health care, with an obvious weakening of social interlinkage and a fading trust in health care institutions.

Any change in terms of scope, quality and prices of health care may and does runs into the wall of disapproval, even judgment; therefore, it is necessary to regulate and legally define health care quality standards in the health system of Serbia and thus precisely determine the quality of service provided and, at the same time, manner of payment, i.e. responsibility for the costs incurred.

In order to reach a financially sustainable health care system in Serbia, it is necessary to analyze different models of funding, implement rationalization and reorganization of methods of funding and

The address of the author:

Ana Gavrilović

彗" anagavrilovic22@gmail.com reexamine the health insurance models in Serbia. The priority concerning the health system financing is the selection of the most adequate method of raising sufficient funds. There are numerous factors which will determine our choice of a particular
\end{abstract}


model of health care system funding in Serbia, among which the following are most important: degree of socio-economic development of the country, fiscal capacity of the country, methods and efficiency of fund raising, support from the political system in its feasibility.

Keywords: health insurance, quality system in health care system, health insurance in the world, models of funding, financially sustainable system

\section{INTRODUCTION}

Health is a state of complete physical, mental and social wellbeing and not merely the absence of disease or infirmity - World Health Organization (1948). This definition equalizes to a considerable extent the notions of "health" and "wellbeing", which implies both physical and mental health, but also social adaptedness and fulfillment.

During the past decade and last year, political and economic instability issues, followed by global economic crisis, cause the health care system in Serbia to become inadequate. In such circumstances, strivings for reconstruction and improvement of health care services in accordance with the population's needs are difficult.

The health system in Serbia suffers from lack of funds and investments but, however, does provide basic services to the citizens. In the Republic of Serbia, health care is provided both through state and private sectors. The Law on Health Insurance of the Republic of Serbia governs compulsory and voluntary health insurance. The Republic Fund for Health Insurance (RFHI) is in charge of managing and providing the compulsory health insurance while voluntary insurance may be provided by the means of private insurance. Expenditures for health care in $€$ per capita oscillated in the period 2006 - 2010 both in their total amount and in each of the components taken into account: the expenditures of the Republic Fund for Health Insurance, public expenditures and private expenditures for health care. In dinar amounts, health care expenditures rose, along with the stable share in GDP, after an increase in 2007. However, in 2009, due to a slower growth of health care expenditures, a negative rate of GDP and a more expressed decrease of dinar to Euro exchange rate, the total health care expenditures per capita in Euro were inferior to the year before. The total health care expenditures in
2010 in Serbia stabilized at the level of $€ 412$, i.e. $\$ 546$ per capita. The expenditures incurred by the Republic Health Insurance Fund were $€ 240$ per capita, while the public expenditures for health care were equivalent to $€ 255$ per capita in 2010. The growth rate of private expenditures for health care in the considered period was higher in comparison to the other ones, but slowed down in 2009, so that in 2010 they also stabilized at the level of $€ 157$ per capita. (IPH, 2012, pp. 19-63)

The share of total health care expenditures in GDP increased in 2007 for one percentage point and stabilized in the following years at $10.4 \%$, with a slight increase to $10.5 \%$ in 2009 . The share of health care private expenditures, after an increase by half a percentage point in 2007, preserved the level of $4 \%$ of GDP. The share of health care expenditure of the Republic Health Insurance Fund in GDP in the examined period was approximately $6 \%$ - it increased in 2007 by half a percentage point and slightly oscillated during the following two years. The share of health care public expenditures in GDP was 6.4\% in 2010 with a similar changing pace in the examined period.

When it comes to allocations for health care expressed as percentage of GDP, Serbia is above the average of the European Union, with its $10.4 \%(9.88 \%$ in 2010$)$, i.e. approximately at the level of Belgium, Austria, Greece and Bosnia and Herzegovina. Serbia allocates a relatively greater amount for health care (as percentage of GDP) than a variety of countries: Albania, Bulgaria, Croatia, Czech Republic, Estonia, Finland, Hungary, Latvia, Lithuania, Luxembourg, Montenegro, Poland, Romania, Russia, Slovak Republic, Macedonia, Turkey etc.

However, in comparison to the EU countries, some other European countries and the average in the EU countries, the Republic of Serbia allocates a small absolute amount of funds for health care. (IPH, 2012) 
Unfortunately, low GDP of Serbia, in particular in conditions of crisis, points out that the real amount of money allocated for health is more than insufficient for the population's needs and for the system of health care institutions under current organization. Total incomes of the Fund for Health Insurance for 2009 were $1,864,370,458$ EUR. Social contribution funds represent $69 \%$ of the amount while budget transfers from the Ministry of Health make $1.5 \%$. Salaries for 104,000 employees had the largest percentage in the expense structure $-48 \%$, costs of health care services (energy generating products, vaccines, medications, supplies) $32 \%$, prescription drugs $-13 \%$, sickness benefits and travel costs $-2 \%$ etc. In 2009 , the amount of 27,319,954.73 EUR was allocated from the Ministry of Health's budget for the Preventive Health Protection Program, which is $49 \%$ of the total budget of the Ministry. Capital investments are generally financed from the budget or from donations. (WHO, 2010)

Gross domestic product is the most important macroeconomic aggregate and indicator of economic development and macroeconomic stability as well. It is the measure of total economic activity of all resident institutional units, whereby both production of material goods and providing all kinds of services are taken into account. The GDP per capita was $€ 3,857$ ( $\$$ 5,277 ) in 2007, while in 2008 it attained $€ 4,445$ $(\$ 6,498)$. The following year, 2009 , as a result of the world crisis, the majority of economic sectors experienced a considerable fall of activities and the overall economic growth rate was negative ($3.5 \%)$. The GDP growth rate in Serbia in 2010 was modest: $1.0 \%$, whilst in 2011 , the commenced growth continued, the rate being $1.6 \%$. This growth was based primarily on the growth of industrial and agricultural production, building industry, transport and telecommunications, from the point of view of production and on the growth of investments, from the point of view of expenditures. Almost three fourths of GDP were generated by the socalled tradable sectors. The total GDP was estimated to $€ 31.143$ billion. The GDP per capita was estimated to be $€ 4,290$ (\$5,964) in 2011.

In 2011 the average net wage in Serbia was RSD 37,976 , which is higher than in the previous year, indexed in EUR. The effective growth rate of net wage in 2011 was $0.2 \%$. (IPH, 2012)

\subsection{Purpose of the paper}

This paper was written to point out critical points in the health system of Serbia, problematic parts requiring analysis. It also compares it with differently organized health systems and finds new models of functioning through a necessary reform the health system in Serbia.

\subsection{Methodology of work}

This paper was written based on the experience gathered in direct professional contact both with beneficiaries of health care services and health care system staff and results gathered by a concrete research.

Statistical methods and modeling methods were used in the research since it deals with a social phenomenon, activities and conditions in the health care system

Additionally, deductive method was also used, as well as analysis of particular forms of the subject of this paper. Further, in the conclusion phase on the phenomenon, induction and synthesis method was applied, and in order to gain conclusions on essential characteristics of particular manifest forms, methods of concretization and abstraction were used.

For a relevant comparison of health care systems and certain elements of health systems in other countries, comparative method was used.

\section{HEALTH INFRASTRUCTURE (NUMBER AND EQUIPMENT OF HOSPITALS)}

The national health system is organized on three levels. The term "health system" denotes activities which include health sector and a set of other sectors (economic and social) which altogether participate in providing health care to the population. (Tasić, 2002)

Primary health care is provided by 161 primary health care institutions and health infirmaries. Secondary and tertiary health care is available in 42 general hospitals, 15 specialized clinics, 23 independent institutions and clinics, 5 health centers and clinics, 4 clinical centers and 59 other health institutions. In 2011, the health care service of the Republic of Serbia employed 113,384 persons. 27,059 employees were with 
university education. Of those, $21,030(77.7 \%)$ are doctors, 2,227 (8.2\%) dentists, 2130 (7.9\%) pharmacists and 1672 (6.2\%) are other professionals.

Of all the doctors, in the Republic of Serbia 5,669 are non-specialist doctors (27\%), of whom 3,387 are medical doctors (16.1\%) and 2282 are in specialist training $(10.9 \%)$. The total number of specialists is $15,361(73 \%)$.

The structure of employed doctors by sex is the following: $35.8 \%$ are male and $64.2 \%$ are female doctors. Of the total number of 2,227 stomatologists, $54.9 \%$ are specialists.

Health care institutions employ a total of 2130 pharmacists, of whom $340(16 \%)$ are specialists.

In 2011, there was a total of 8268 health workers and associates with college education in health care institutions, of whom 4391 (53.1\%) nursesmedical technicians. 49,930 health workers and associates have secondary education, of whom $35,490(71.1 \%)$ are nurses-medical technicians.

Health care institutions employed a total of 27,676 non-medical staff, of whom 9465 (34.2\%) administrative staff and $18,211 \quad(65.8 \%)$ of technical staff. (IPH, 2012)

Private health sector is developed but not incorporated in the national health system.

Health insurance (preconditions and costs) An employee is entitled to health insurance based on temporary or permanent employment; also, retired persons are entitled to health insurance based on the contributions paid during working life. The employer is obliged to pay contributions to the RFHI and a health insurance booklet with extended validity will be issued to the insured person.

Unemployed persons and other categories - the first step is possession of an employment booklet with employment record; the second step is registration at the National Employment Service according to a person's place of residence. The third step is applying for health insurance at branch offices of the RFHI according to the place of residence.

Health insurance is free of charge for unemployed persons registered at the National Employment Service.

\section{HEALTH SYSTEM FUNDING}

In general, financing deals with the mobilization, accumulation and allocation of funds to cover the health needs of the people, individually and collectively. (Anon, 2010)

The financing function in health systems is defined by Murray and Frenk (2001) as "the process by which revenues are collected from primary and secondary sources, accumulated in fund pools and allocated to provider activities". Three subfunctions can be distinguished: revenue collection, fund pooling and purchasing. Revenue collection means the mobilization of funds from primary sources (households, firms) and secondary sources (governments, donor agencies). There are a number of mechanisms through which funds can be mobilized, varying by health systems context, e.g. out-of-pocket payments, voluntary insurance rated by income, voluntary insurance rated by risk, compulsory insurance, general taxes, earmarked taxes, donations from NGOs and transfers from donor agencies. In order to share and reduce health risks, funds can be pooled through various forms of health insurance. Purchasing is the allocation of funds to cover the costs (staff, durables and running costs) of specific health service interventions by health providers (institutional or individual) (Murray \& Frenk, 2001). The way these subfunctions are organized and executed has an impact on the access to health services. (WHO, 2010)

It is essential to mention that a health care reform will not solve all the problems in the health system overnight because the state has no sufficient money to finance all the rights to health care prescribed by the law. The population of Serbia, guided by a long-lasting system of a health system of 'welfare', oversees the current difficult situation affecting the overall social system, along with the health system within it. Expectations go as far as taking for granted a health care which is absolutely free of charge, assuming that the health care system can and does solve all the health problems of people.

The amount of money generated from incomes (regardless of method of funding), mostly depends on the amount of money that a country is ready to allocate, in terms of other goals 
(higher labor price) in order to increase the consumption within the health system. It is worth emphasizing that all sources of financing are, directly or indirectly, generated from citizens: financing from the State Budget, compulsory health insurance, private insurance, direct "outof-pocket" payment, financing from community funds, donations, loans etc.

Methods of funding vary from Semashko to Bismarck model. The Semashko model, with universal right to health care free of charge and a centralized system was part of a planned economy with domination of specialized institutions. (WHO, 2013) The Bismarck model is a market-oriented model with decentralization (contract model), where primary health care acts as a gatekeeper to the system. (PNHP, 2013) This model features effect-based payments, evidence-based medicine and the capacity (excessive) is visibly reduced.

It is important to understand that all the money directly or indirectly originates from the citizens by:

- Financing from the State Budget

- Compulsory health insurance

- Direct payment 'out-of-pocket'

- Financing from the community funds

- Donations, loans etc.

Health care in Serbia is mainly financed by mandatory contributions to a social health insurance scheme. The National Health Insurance Fund (HIF) is responsible for financing the system. Mandatory health insurance premiums are levied on salaries of employees (employer and employee pay equal portions) as well as from farmers and the self-employed.

Another source of financing is private expenditures for health, mainly out-of-pocket payments for medicines. Much private expenditure is related to medicines. In Serbia out-of-pocket payments for health (as a proportion of the total health expenditure) are relatively high. (WHO, 2001)

Private funding is more or less completely based on out-of-pocket payments and is supplemented by contributions from a small number of major companies which have (and fund) their own institutions which specialize in the treatment of occupational diseases and also provide primary care services. More than $90 \%$ of public costs are financed through the Republic Health Insurance Fund (RHIF) or inter-departmental transfers via the RHIF. Similar coverage is envisaged for those who are entitled to health care services by military service providers.

Collected funds are centrally pooled by the HIF and redistributed in line with regulation for contracting with health institutions. The HIF is obliged to contract all health care services from delivery institutions that are on an official list.

Contracts with the HIF include a work plan developed by the Regional Institute of Public Health. Payments to providers are primarily based on inputs instead of service delivery. Thus, salaries of health care workers currently contain very few incentives for good performance. There are plans to change this system by contracting facilities and by paying health workers within a capitation-based payment scheme.

According to the ongoing process of decentralization in the PC - Primary care (sector, municipalities increasingly own facilities and equipment, and are therefore responsible for capital investments.

Service provision: The HIF guarantees access to a relatively broad package of health services to the entire population. Scope and content of care are legally defined and include preventive, curative, rehabilitative, inpatient and outpatient specialist care, and PC including prescription drugs, home care and medical transport. Despite the initial strong emphasis on PC, the system evolved such that curative services were largely carried out by specialists and in the hospitals. The frequent referrals by PC providers to the secondary and tertiary levels resulted in a loss of PC skills, to the point where not all physicians feel capable of performing the more comprehensive chosen doctor duties. (IPH, 2011)

A combined model of financing is mostly applied based on which the following is determined: how much money will be collected, who is responsible for financing, and who controls the funds as well as the possibility of cost increase control. Choice of a modality for financing the health system shall depend on several crucial items, such as: degree of socio-economic development of the country, 
fiscal capacity of the country, efficiency of fund raising, political feasibility.

Health insurance system considerably differs from country to country. In many countries in the world there is no compulsory health insurance and the health care system absorbs resources by general taxing (Scandinavia and United Kingdom). There is also a form of voluntary private health insurance, offering the possibility of health care in private sector (private clinics and private departments, accelerated medical treatment in hospitals).

In the USA, health insurance is based on insurance policy type -market-oriented model. The influence of market orientation is evident also in countries such as Finland or Sweden. In these countries health care is financed from taxes and is tightly related to the public sector, which directs it towards objective and function of public organizations financed from taxes. (Timo \& Janne, 2012)

Social insurance in Serbia (compulsory health insurance) is a model of obligatory social insurance, amounts of money paid being linked to the amount of income, whereby it requires contributions both from employers and employees. The service is free of charge for a patient on the spot where it is provided and the health care level is not connected to the contributions paid. Due to its connection to the income and lacking any connection with the benefit provided, it actually represents an alternative way of taxing. It could be replaced with higher taxes on personal incomes as well and on corporation incomes. The insurance does not cover all the costs of health care so that the burden falls onto general taxes. State or local budgets cover the costs of epidemiological control, medical staff and research. Construction and maintenance of facilities and purchase of equipment is the responsibility of the state or local budgets. The Government covers insurance costs for groups not earning any money - retired people, children, persons with disabilities, unemployed persons etc.

A great problem is that employers experiencing financial difficulties do not pay compulsory contributions to health insurance funds and the Government, not always giving adequate payments for its contributions for those people who do not pay for themselves. Thus, a circle of debt is formed where funds do not make payments to hospitals, general practitioners and other health service providers, who, on the other side, delay payments for the costs to suppliers, such as companies delivering medications and energy generating products.

Social health insurance is a contract between the client, as part of the population, and the insurance, as part of the system, according to which the insurance refunds a particular amount to the insured person, or, most frequently, bears the costs issued by the health care provider, entirely or partly. There are two distinctive features between social and private insurance. Firstly, social insurance is compulsory. Everyone belonging to a certain group must be insured and must pay certain amount of money as contribution. Health contributions are paid according to the possibilities and health care is used according to the needs.

Generally, health care contributions are calculated as percentage of gross salary, regardless of the health risk. When a person (or a number of persons) pay(s) the contribution, they are entitled to certain benefits (health services, sick leave etc.). Secondly, social insurance and benefits are prescribed by law and sublegal acts. Therefore, this gives space to speak about social contract between the covered population and the system.

The insured persons consent to pay certain amount of money with the assurance that this money will be used in a fair and efficient manner in order to finance the health care for all those who are part of this system. Social insurance was not designed to provide universal coverage of population.

Some economists consider social insurance as a program financed out of taxes, mainly because paying contributions is mandatory. On the other hand, there are essential differences between the insurance financed out of contributions from general tax and the social insurance:

Social insurance is not a right of all people, it covers only those entitled to it and meeting the minimum of requirements in terms of contributions. 
People understand that they pay premiums for contributions in exchange for the right to benefits. In other words, benefits are not something provided by the state.

The paid benefits are reserved for programs and separated from general tax.

Social insurance is expected to maintain its solvency and thus provide a higher degree of transparency and responsibility towards the beneficiaries. The capacity of social insurance, from the point of view of fund raising, depends on the possibility to raise money (contributions) by employers and employees covered by insurance. Experience has shown that social insurance can be efficient in countries with most of the activities in the formal sector and companies with 10 and more employees. (RHIF, Principi finansiranja, 2013) The only obligatory payment made by the insured persons, unless they are exempt from taxes, is the participation fee for those health services for which such payment is obliged to issue an invoice for each paid participation fee, as prescribed by the Republic Health Insurance Fund. If an insured person considers the participation fee, i.e. the health service, to be required for payment for no justifiable reason, he/she is entitled to submit to his/her competent branch office a request for refunding. The total amount of participation fee which an insured person can pay during a calendar year is limited to maximum half of the monthly salary, i.e. pension paid for the last month in the calendar year. For the insured persons receiving no monthly salary or pension, the amount is limited to maximum half of the average net wage in the Republic paid in the last month of the calendar year. Certain categories of citizens are exempt from paying participation fees for health services for which such payment is envisaged (e.g. examinations by the selected physician, medications with fixed fee or RSD 50, laboratory analyses, rehabilitation, percentage share in price of medical devices.) (RHIF, Participacija, 2013)

Financing from the State Budget - The Government receives its income from diverse taxes and fees, such as income tax, company income tax, value-added tax, etc. As for general tax, the total income generated from taxes is used for financing a range of Government's activities. In such circumstances, the health system must compete for funds with all other programs and sectors financed by the Government, such as education, defense... Health is most often less important in comparison to certain other fields.

Private health insurance - Private health insurance means that people decide on voluntary basis if they will buy health insurance in order to provide safety in case of illness. This insurance can be purchased on individual or group basis. The advantage of private insurance lies in competitiveness, which stimulates efficiency in delivering health services. Private health sector is developed but not incorporated in the national health system.

Private health insurance may be purchased on individual or group basis. There is a growing interest for different forms of private insurance in the world. Primarily, private insurance can mobilize additional funds. Secondly, those who do not pay are not covered by the services, so there is no problem of tax evasion. Also, advocates of private insurance claim that people can choose which insurance plan they will take and a competitive market should respond to this situation with a wide range of products. One of the arguments in favor of private insurance relies on competiveness aiming at improving efficiency. The pre-requisite is that competitive markets lower down the prices of health care. Additionally, those providers facing the issue of lower income will see this as a stimulation to reorganize their business, in order to reduce the prices. (RHIF, Principi finansiranja, 2013)

'Out-of-pocket' financing by beneficiaries This model of funding envisages that individual patients pay directly 'out of their pocket' to the health service provider for the material and services they have received. These costs may not be reimbursed from the insurance. This form of financing considerably reduces unnecessary use of health services but also leads to collecting additional funds. This model is considered to be highly regressive toward persons with poor health and low incomes. This factor, among others, contributes to an increasing inequality in access to health care. (Walters \& Suhrcke, 2005) 
Out-of-pocket' financing by beneficiaries This model of funding envisages that individual patients pay directly 'out of their pocket' to the health service provider for the material and services they have received. These costs may not be reimbursed from the insurance.
Financing by the local community - is generally organized through control of the primary health care. Financing by the local community has limited capacities for raising higher amounts of money but is used efficiently in reaching important results in primary health care in poor and undeveloped countries.

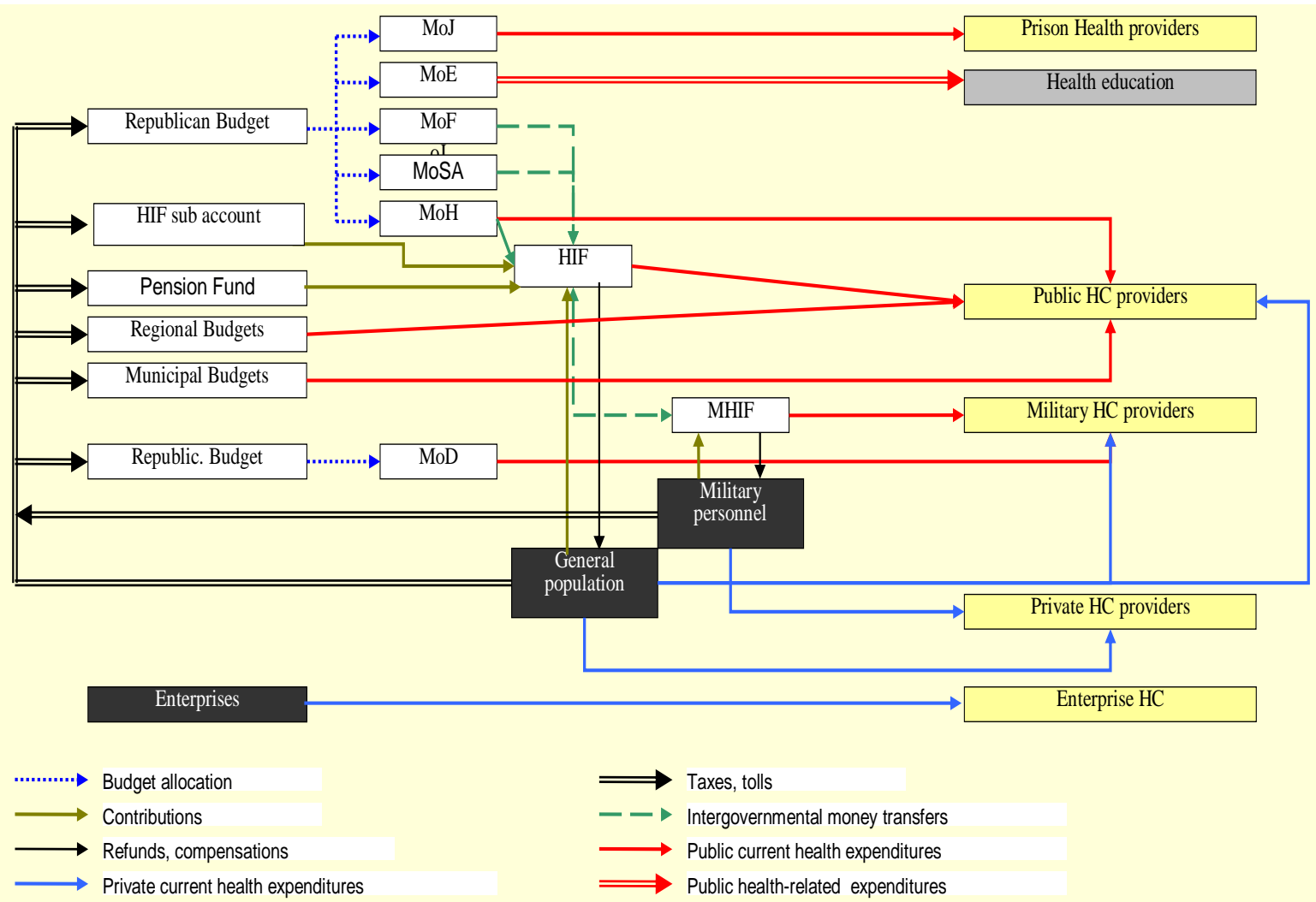

Graph 1 Money flow in Serbian health system (Gajić-Stevanović, 2009)

\subsection{Common problems of health care system}

Problems affecting our health system are to be found in both internal and external environment.

The most common problems are marked with financial issues but there are also numerous weaknesses in terms of organization and functioning of health care:

- non-functionally organized health service,

- management lacking necessary managerial skills and adequate management education,

- inadequate method of health service payment and vague method of financing the health institution,

- needs and priorities in health care are poorly planned;
- large percentage of non-medical staff in health institutions and medical management (without necessary managerial competences),

- poor quality IT system,

- all power in health and health institutions is centralized and belongs to state/political party organizations and institutions,

- health capacities beyond the frameworks of economic possibilities of society, outdated equipment and degradation of buildings dealing with health,

- low salaries for medical staff, which results in low professional satisfaction, lack of motivation for a high quality and efficient work;

- absence of quality assessment of health work;

- pharmaceutical mafia, absence of national drug policy and inadequate control; 
- inadequate way of fund allocation with priorities and levels of health care;

- health system management does not correspond to the modern concept of health system organization, particularly in terms of planning;

- absence of timely and correct information serving as support for decision making and budget control, which diminishes transparency of the overall health care system.

Health service providers in primary health care receive standard payments per capita for the patients they register. Problems with such an organization are evident because payments in primary health care do not change based on the quality and quantity of the services provided, which engenders the tendency encouraging referral of patients to hospitals or units for specialized treatment. This destimulates the decision on focusing health care on primary level, i.e. the decision to provide major part of health services in primary health care, which is more efficient and appropriate.

\subsection{Health care quality}

All countries face challenges to ensure access, equity, safety and participation of patients within the available resources, and to develop skills, technology and evidence-based medicine. In the reform of health systems and providing services, most countries assign crucial role to improvement of health care quality and introduction and standardization of the health quality system.

A very important and necessary component of health care and each activity implemented in health and medicine in general is quality, which is impossible to examine separately from two other components: scope of activities and costs, which are tightly interconnected. A special attention is paid to quality in periods with limited resources for health care and budgetary constraints and quality is specially emphasized in periods of its absence.

High quality medical care is explained most comprehensively by Ovretveit's definition (involving organizational, political and financial interests): High quality health care is "...fully meeting the needs of those who need the service most, at the lowest cost to the organization, within limits and directives set by higher authorities and purchasers". (Ovretveit, 1995)
Therefore, a high quality medical care is not the one achieved at any price, but the one that - by meeting the patients' needs together with professional needs and goals - makes use of the resources in the most efficient way. Finally, health care cannot be of good quality if it fails to meet legal, ethical, contractual and other obligations. This definition is the starting point of the conclusion that high quality health care is a result of opposite requirements of different interest groups.

\section{Quality in health must be analyzed and implemented in three dimensions:}

1. degree of possibility;

2. level reached by providing services to beneficiaries;

3. success in satisfying certain needs of the system and the beneficiary.

Key determinants of the dimensions of a high quality health care are: efficiency, accessibility, efficacy, continuity, equity, acceptability, timeliness, appropriateness, availability, safety, effectiveness...

In order to achieve representativeness of the health care system, it is necessary to implement strategies of work quality and safety improvement of both patients and health workers. Reaching this objective implies necessity of elimination or at least reduction of several potential identified irregularities, such as:

a) unequal delivery of quality in different health services,

b) time of waiting for certain medical procedures and interventions,

c) beneficiaries' dissatisfaction regarding health services received,

d) inefficient use of health technologies,

e) insufficient skillfulness for using modern information technologies as well as out-ofdate information system,

f) dissatisfaction of health care system staff,

g) bad quality of health services increases costs in the health system,

h) impermissible varying score in outcomes related to the health of the treated patients.

i) It is difficult to reconcile different attitudes, points of view and expectations concerning quality degree between legislation makers in health, funders, health workers, management of medical institutions and patients, as crucial links in the chain. The 
interests of the mentioned groups are always mutually opposed.

It is not difficult to conclude why the topic dealing with the quality of health care is complex to such an extent and why introduction of quality system in health has such a slow progress.

\section{NECESSITY OF HEALTH SYSTEM REFORM}

\section{Basic goals of reform are:}

- basic goal of the reform is bringing the health system to the state of optimal functionality in order to attain highest positive effect on health condition of the population within the available resources;

- equity in using and financing the health care system; allocative, technical and administrative efficacy of the health care system;

- financial and institutional sustainability of the system;

- constant improvement of quality of work and services offered to beneficiaries;

- acceptability of the health care system to beneficiaries and health service providers

- increasing health system efficacy through rational and available resources,

- application of modern medical technologies.

\section{Proposals for directions of reform implementation:}

- Legal system and state authorities must accept the attitude that health care is the primary system in functioning of a country. A nation of poor health is incapable of reaching economic or any kind of development.

- Property transformation (with assessment of state and social interest in health and the share which will be ceded to the private sector).

- Higher efficacy in implementation and control of compulsory health insurance payments as well as establishment of voluntary and private health insurance. Legal system should incorporate proper measures which would penalize avoiding payments to the Republic Fund for Health Insurance.

- Control of medical drug consumption and establishing drug consumption policies (fight against illegal activities of the pharmaceutical mafia);

- Skillful management of health organization managing structures with adequate anagement education). Management according to the modern conception of health system organization, with emphasis on planning; It is considered that top management of a company needs a plan to explain certain values of planning to their directors. (Kotler, 1988)

- Increasing participation of insured persons in the amount of $15-20 \%$ (percentage share in price of implants and medical devices...)

- Integration of private practice into financing and into the health care system itself, Policy of public and private sector cooperation is the key for a successful cooperation and credibility; (MMFRSG, 1999)

- Decentralization - the basis of the health care system is to be transferred and primary health care is to be stressed out (municipality level). This will lead to mobilization of additional funds from the local level; Political parties' influence on decisions made in the health care system will decrease; financial risk is shared equally by the municipality and health administrative regions. (Lasley, 1991)

- Emphasis on preventive instead of curative medicine.

- Implement better quality control of health services provided;

- Include private practice in citizens' primary health care based on subcontracting;

- Reorganize hospital capacities (five beds per 1,000 inhabitants);

- Dental health care ought to be restored to $50 \%$ of funding by the Fund for Health Insurance based on principles of humanity and an obvious decrease in dental health of the nation;

- Modernize health information system because timely and reliable information are the key of the health care system reform and a basis for decision-making, managing, planning, monitoring and implementation of reforms. The national information system should be an information-communication system serving for managing the health care system and be a synthesis of all information system networks established by health institutions, insurance funds and regional centers.

\section{CONCLUSION}

Health is one of the most important assumptions for a prosperous life of population and this must be acknowledged as a priority of health care development strategy. The health of the population of Serbia is of key interest for the 
state and the most relevant item of an accelerated political and economic development. Health policy should represent the basis for legal and action programs, with the aim of improving efficacy and quality of health care and integrating health system in the European and global process of health development.

Health problems also affect functioning of family, community and society in general, and the quality in providing health services represents the pillar of safety for all social groups; therefore, upgrading standards and quality criteria in health legislation is indispensable and urgent.

The problems of the current system may cause considerable negative consequences for citizens and their families. Medical science along with costs for treatment and prevention grow faster than the economic basis of society. Thus, it is necessary to introduce adequate forms of health system financing which will provide access to the necessary health care, and simultaneously distribute the financial risk so that the population avoids being financially threatened to a considerable extent in case of illness.

A considerable improvement of health care can be achieved by a planned restructuring of the existing resources.

Finally, one must not forget that health is not financed solely from the Fund for Health Works Cited
Insurance. From one side, the amount of paid services which are not covered by the Fund in the state health sector was 6,635,989,021.29 RSD in Serbia in 2010 and special programs for increasing this amount must be developed. Also, a very important problem of the health care system in total is the fact that private health institutions are not integrated in the system of primary, secondary and tertiary health care. The turnover of 3033 private health practices (1268 infirmaries and 1765 dental practices) was $12,274,899,205$ RSD in 2010 , which is only a part of the money, bearing in mind incomplete fiscalization and tax records of the private sector's work.

The contribution to improvement of health system is to be given by health education and preventive measures decreasing risk factors and diseases among the population. It is necessary to make careful, planned and concrete efforts to establish mutual understanding between institution and its public - patients, i.e. environment. (Pavlović, 2003.)

The global economic crisis is a reality but at the same time a potential pretext for continuing a longtime unreasonable and inefficient functioning of health care. Health care must be integrative and health must become a "joint venture" in order to genuinely improve health outcomes and health services. (in (Stambolović, 2008)

Anon. $(2010,1214)$. Health systems financing. Retrieved from World Health Organization: http://www.who.int/healthinfo/systems/WHO_MBHSS_2010_section5_web.pdf

Gajić-Stevanović, M. (2009, 06 03). Health care system and spending in Serbia. Retrieved from Health Systems 20/20: http://www.healthsystems2020.org/content/impact/detail/2285/

IPH. (2011). Evolution of the organization and provision of the primary care in Serbia, Primary care in the WHO European Region, A survey-based project in the regions of Vojvodina, Central Serbia and Belgrade. Retrieved February 15., 2013, from Institut za javno zdravlje " Dr Milan Jovanović Batut": www.batut.org.rs/download/publikacije/pub2011.pdf.

IPH. $(2012,10)$. Health statistical yearbook of Republic of Serbia 2011; Selected health indicators for year 2011. (T. Knežević, Ed.) Retrieved 02 15, 2013, from Institut za javno zdravlje "Dr Milan Jovanović Batut": http://www.batut.org.rs/download/publikacije/pub2011.pdf

Kotler, P. (1988). Upravljanje marketingom. Zagreb: Informator.

Lasley, I. (1991). Financial Accountability and Management. Accounting Reasearch in National Health Service.

MMFRSG. (1999). Public-Private Collaboration in Health Information Policy. Milbank Memorial Fund Reforming State Group. Retrieved from Milbank Memorial. 
Murray, C., \& Frenk, J. (2001). World Health Report 2000: a step towards evidence-based health policy. Geneva: Lancet. Retrieved from http://www.popline.org/node/177038

Ovretveit, J. (1995). Health Service Quality. An introduction to Quality Methods for Health Services. Oxford: Blackwell Science.

Pavlović, M. (2003.). Odnosi s javnošću. Beograd.

PNHP. (2013). Health Care Systems - Four Basic Models. Retrieved from Physicians for a National Health Program:

http://www.pnhp.org/single_payer_resources/health_care_systems_four_basic_models.php

Radulović, V. (2011). Usluge primerene potrebama pacijenata. Danas.

RHIF. (2013). Participacija. Retrieved February 25, 2013, from Republic Health Insurence Fund: http//www.lat.rfzo.rs/index.php/participacija.html

RHIF. (2013). Principi finansiranja. Retrieved February 25, 2013, from Republic Health Insurance Fund: http//www.lat.rfzo.rs/download/Principi finansiranja-lat.pdf.

Stambolović, V. (2008). Alternative medicine during millennial transition. In \&. A. Tatyana BenishevaDimitrova, L. Kovačić, \& L. Zaletel-Kragelj (Eds.), Management in health care practice (pp. 368-377). Zagreb: Hans Jacobs Publishing Company. Retrieved from http://www.snz.unizg.hr/ph-see/Documents/Publications/FPH-

SEE_Book_Management_in_Health.pdf

Tasić, L. (2002). Farmaceutski menadžment i marketing. Beograd: Farmaceutski fakultet .

Timo, H., \& Janne, J. (2012). Uloga finansiranja zdravstva iz budžeta u ugovornom upravljanju. Projekat Vlade Finske. Beograd.

Walters, S., \& Suhrcke, M. (2005). Socio-economic inequalities in healt and health care access in central and eastern Europe and the CIS: a review of the recent literature. WHO European Office for Investment for Health and Development.

White, T. (1993). Manegement for Clinicians. London.

WHO. (1948, 04 07). WHO definition of Health. Retrieved 2013, from World Health Organization: http://www.who.int/about/definition/en/print.html

WHO. (2001). Health System Performance: Glossary. Retrieved February 2013., from World Health Organization: http//www.who.int/health-sistems-performance/docs/glossary

WHO. (2001). Health Systems Performance. Retrieved from World health organization: http://www.who.int/health-systems-performance/about.htm

WHO. (2010, 12 20). Evalution of the organization and provision of primary care in Serbia. Retrieved from World Health Organization Regional Office for Europe: http://www.euro.who.int/_data/assets/pdf_file/0005/128849/e94554.pdf

WHO. (2013). Primary health care - Facts and figures. Retrieved from World health organization: http://www.euro.who.int/en/what-we-do/health-topics/Health-systems/primary-healthcare/facts-and-figures

Received for publication: 03.12.2012

Revision received: $\quad$ 05.03.2013

Accepted for publication: 29.03.2013 


\section{How to cite this article?}

Style - APA Sixth Edition:

Gavrilović, A., \& Trmčić, S. (2013, 07 15). Health insurance system in Serbia - quality, reform, financial sustainability. (Z. Čekerevac, Ed.) MEST Journal, 1(2), 114-126. doi:10.12709/mest.01.01.02.11

Style - Chicago Fifteenth Edition:

Gavrilović, Ana, and Snežana Trmčić. "Health insurance system in Serbia - quality, reform, financial sustainability." Edited by Zoran Čekerevac. MEST Journal (MESTE) 1, no. 2 (07 2013): 114126.

Style - GOST Name Sort:

Gavrilović Ana and Trmčić Snežana Health insurance system in Serbia - quality, reform, financial sustainability [Journal] = Health insurance system in Serbia // MEST Journal / ed. Čekerevac Zoran. Belgrade : MESTE, 07 15, 2013. - 2 : Vol. 1. - pp. 114-126. - ISSN 2334-7058 (Online); ISSN 23347171.

Style - Harvard Anglia:

Gavrilović, A. \& Trmčić, S., 2013. Health insurance system in Serbia - quality, reform, financial sustainability. MEST Journal, 15 07, 1(2), pp. 114-126.

Style - ISO 690 Numerical Reference:

Health insurance system in Serbia - quality, reform, financial sustainability. Gavrilović, Ana and Trmčić, Snežana. [ed.] Zoran Čekerevac. 2, Belgrade : MESTE, 07 15, 2013, MEST Journal, Vol. 1, pp. 114-126. ISSN 2334-7058 (Online); ISSN 2334-7171. 